ciated with the post-infarction syndrome and post-cardiotomy syndrome. The problems of differential diagnosis are discussed. Cardiac tamponade was the most serious complication ; but this was uncommon and was rapidly relieved by aspiration of pericardial fluid. No patients required pericardectomy, possibly because corticosteroids brought rapid resolution or possibly because constriction is so rare that it was not encountered in any one of these 41 patients. Furthermore, corticosteroid therapy effectively prevents recurrences, which are common in all forms of "benign" pericarditis.

"Antiheart" antibodies were detected in almost all of the post-infarction and post-cardiotomy cases and in one-third of the idiopathic group. It is concluded that recurrent pericarditis may be provoked by a variety of noxious agents, which lead, in susceptible individuals, to an abnormal immune reaction independent of the primary cause.
REFERENCES

Brigden, W., Bywaters, E. G. L., Lessof, M. H., and Ross, I. P. (1960), Brit. Heart Y., 22, 1 .

Feder, I. A., Hoffiman, J., and Sugar, H. (1950). Amer. F. med. Sci., 220 144.

Fox, T. T., and Messeloff, C. R. (1942). N.Y. St. F. Med., 42, 152.

Gilley, E. W., McCord, M. C., and Taguchi, J. T. (1951). Amer. ? med. Sci., 222, 249 .

Goldfarb, B., Gold, D., Latts, E., Wexler, H., and Wang, Y. (1966) Circulation, 33, 283

Goldman, M. J., and Lau, F. Y. K. (1954). New Engl. 7. Med., 250, 27 S Hedlund, P., Lycke, E., and Tibblin, G. (1962). Acta med. scand., 172 323.

Krook, H. (1954). Acta med. scand., 148, 201.

Jamplis, R. W. (1954). Amer. Y. Surg., 108, 191

Jamplis, R. W. (1954). Amer. F. Surg., 108, 191.
Liu, H. Y., and Garcia, R. (1965). Amer. Heart 7., 69, 677.
Robinson, J., and Brigden, W. (1963). Brit. med. F., 2, 706.

Schoenwetter, A. H., and Silber, E. N. (1965). 尹. Amer. med. Ass., 191 672 .

Schrire, V. (1967). Aust. Ann. Med., 16, 41.

Sokoloff, L. (1964). Mod. Conc. cardiovasc. Dis., 33, 847.

Swan, W. G. A. (1960). Brit. Heart F., 22, 651.

\title{
Effects of Cortisol Deficiency on the Electrocardiogram
}

\author{
M. HARTOG, ${ }^{*}$ D.M., M.R.C.P. ; G. F. JOPLIN,* PH.D., M.R.C.P.
}

Brit. med. F., 1968, 2, 275-277

Abnormalities of the clectrocardiogram (E.C.G.) have long been known to occur in Addison's disease (Coelho, 1932 ; Delius and Opitz, 1935), and an extensive analysis of such abnormalities has been reported by Somerville et al. (1951). Changes in the E.C.G. in hypopituitarism have also been described (Sheehan and Summers, 1949); these abnormalities were reversed by treatment with thyroid hormone and must therefore have been caused by thyroid deficiency. However, others have noted that in some hypopituitary patients the E.C.G. reverted to normal if only cortisone was given (Kosowicz and Roguska, 1963).

We have had the opportunity of studying the effects of cortisol deficiency on the E.C.G. in euthyroid patients with cancer in whom an attempt had been made to ablate the pituitary by needle implantation of radioactive yttrium (Fraser and Joplin, 1961). Since the highest degree of destruction of the gland affords the best chance of a remission of the disease (Joplin, 1965), it was essential to assess pituitary function after operation so that a second implant could be performed in the event of an incomplete ablation. As part of this assessment corticosteroid therapy was withdrawn after operation, and the effect of this withdrawal on the patients' general condition and on serial water diuresis tests was observed. The majority of these withdrawals were done within three weeks of operation, which was too early for significant hypothyroidism to have developed. In those subjects in whom a withdrawal at a later date was performed an assessment of their thyroid state had previously been made, and those thought to be hypothyroid had been treated with thyroxine. Thus the effect of cortisol deficiency alone on the E.C.G. could be followed, both during corticosteroid withdrawal and during subsequent repletion, where this was necessary.

\section{Patients Studied and Methods Used}

Patients Studied.-The patients consisted of 26 women suffering from disseminated breast cancer and two men with disseminated cancer of the prostate.

Clinical Management.-In most cases cortisone administration was discontinued on the 10th postoperative day. In some a withdrawal was performed during a later admission for general

* Royal Postgraduate Medical School, London W.12. assessment. After withdrawal of cortisone a careful watch was maintained for clinical evidence of corticosteroid deficiency such as anorexia, nausea, lethargy, fever, or hypotension. As soon as corticosteroid deficiency was diagnosed the patients were rapidly repleted with prednisone. The standard repletion regimen was $20 \mathrm{mg}$. of prednisone by mouth initially, followed by 5-mg. hourly for six doses, and then $5 \mathrm{mg}$. four-hourly until the patient was fully recovered, which usually took less than 24 hours. Adrenocortical function was assessed by means of serial water diuresis tests in which a litre of water was administered. Normal subjects excrete over $75 \%$ in four hours, whereas patients with adrenal insufficiency usually excrete less than $40 \%$ during this period (Joplin, 1965). In some patients estimations of urinary 17-oxygenic steroids were performed by the method of Norymberski et al. (1953). However, many of these seriously ill cancer patients had low levels of 17-oxygenic steroids before operation, so that the usefulness of these estimations during the period of corticosteroid withdrawal was limited.

E.C.G. Recording.-Complete E.C.G.s were taken on all patients before operation; only those whose tracings were normal before operation have been included in this paper. Tracings were recorded serially throughout the period of cortisone deprivation, and also during the subsequent phase of repletion when this was performed. The majority of the E.C.G.'s were taken with a Mingograf (Elmquist) machine. This instrument has a high input impedance, which minimizes differences in resistance between skin and electrodes. Owing to the difficulty of obtaining reproducible tracings of the precordial leads, our analysis is based solely on the standard and unipolar limb leads. Most of the E.C.G.s have been analysed and measured by a cardiologist who was unaware at the time of the clinical state of the patient. The components of the E.C.G. which were measured were the $P-R$ interval, the width and amplitude of the QRS complex, the Q-T interval, and the amplitude of the $T$ waves. The height of the $T$ wave in the serial tracings was expressed as a percentage of the height before cortisone withdrawal, this value being taken as $100 \%$. In each case the E.C.G. was reviewed as a whole to ensure that apparent changes in the size of the $T$ wave were not due to obvious changes in the vector. In all patients studied any change of the $T$ wave in the axial limb lead was reflected throughout the other available leads. 


\section{T-wave Changes}

The most frequent abnormalities developing during cortisol insufficiency were in the $T$ waves, and these are described first. The $\mathrm{T}$-wave changes are described separately for the group of patients who showed symptoms of corticosteroid deficiency on cortisone withdrawal and the group who did not.

\section{Corticosteroid-dependent Patients}

Sixteen patients developed symptoms of corticosteroid deficiency on withdrawal of cortisone; in the majority of them ancillary test evidence was obtained, supporting the diagnosis of corticosteroid deficiency. Thus 8 out of 10 patients who had a normal water diuresis test before withdrawal showed values of less than $40 \%$ during the withdrawal, the values in the other two being 44 and $47 \%$. Eight patients had estimations of urinary 17-OGS performed at least 24 hours after the withdrawal of cortisone; the levels were less than $4 \mathrm{mg} . / 24$ hours in all of them.

Fig. 1 shows an example of changes in the $T$ waves which were observed in a patient with metastatic breast cancer. Soon after cortisone was stopped there was a reduction in the height of the $T$ wave, and later, when symptoms of corticosteroid deficiency became definite, the $\mathrm{T}$ waves became inverted. On repletion with prednisone the $\mathrm{T}$ waves became upright again (Fig. 1).

The changes in the height of the $T$ waves of all the 16 corticosteroid-dependent patients are shown in Fig. 2. Thirteen showed a reduction in the amplitude of the $\mathrm{T}$ wave of more than $50 \%$ of their initial height, while the remaining thiee subjects showed a lesser reduction.

Following the subsequent prednisone repletion, the height of the $\mathrm{T}$ waves of 8 of these 13 patients increased to values within $25 \%$ of the initial value. In four this improvement had occurred by the second day of repletion, while in one it occurred only after 13 days of treatment. In the remaining five patients the height of the $\mathrm{T}$ wave remained below $75 \%$ of the initial height for periods of observation ranging from two to seven days, though in four some increase in height was discernible.

There was no evidence from tests of pituitary function that the three patients whose $\mathrm{T}$-wave voltage fell by less than $50 \%$ during steroid withdrawal had sustained a lesser degree of pituitary damage than had the remainder of the group.

When the $T$-wave changes of the 13 patients showing a fall in amplitude to under $50 \%$ were considered in terms of the measured amplitude, it was found that the magnitude of the reduction varied between 0.8 and $3.7 \mathrm{~mm}$., the mean reduction being $1.8 \mathrm{~mm}$.

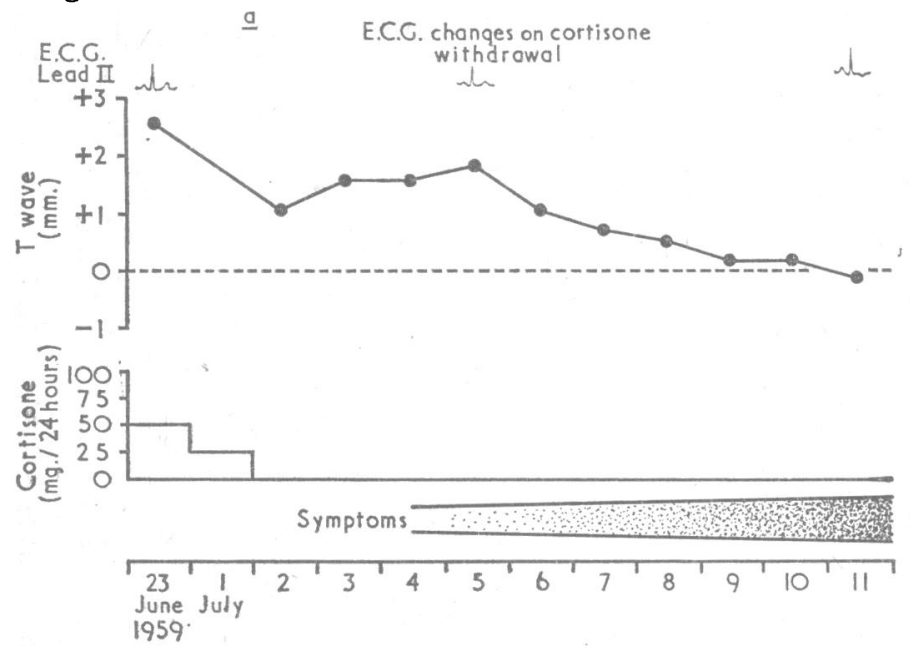

\section{Corticosteroid-independent Patients}

Twelve patients remained well throughout periods of cortisone withdrawal ranging from 5 to 40 days. Six of them had a normal water diuresis test before the withdrawal; in three the values remained normal when tested during cortisone deprivation, while in the other three the values fell to 41,40 , and $40 \%$. These changes suggested that these three patients had considerably impaired endogenous cortisol production, though the absence of symptoms indicated some residual function of the adrenal cortex.

The changes in the height of the axial $T$ waves in the 12 patients are shown in Fig. 3. In 10 patients there was either no reduction in the height of the $\mathrm{T}$ waves or only a slight reduction, the value still being more than $70 \%$ of the initial height before withdrawal. One patient showed a temporary decrease in the height of the $\mathrm{T}$ wave, which subsequently rose to $80 \%$ of the original height despite continued cortisone deprivation. This patient had a normal neck uptake of radioiodine, indicating a relatively minor degree of pituitary destruction. In the twelfth patient there was a pronounced fall of $1.9 \mathrm{~mm}$. in the height of the $\mathrm{T}$ waves to less than $50 \%$ of the original value, and this was maintained throughout eight days of withdrawal. She had an abnormal water diuresis test of $31 \%$ on the seventh day of withdrawal, which suggested a

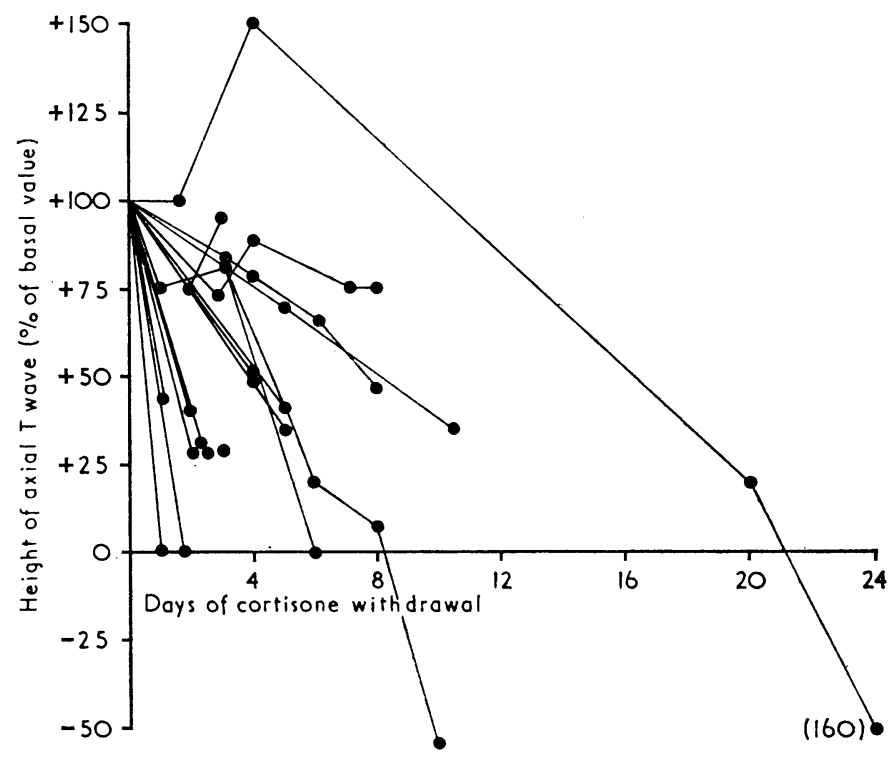

FIG. 2.-Effect of cortisone withdrawal on height of axial $\mathrm{T}$ wave in 16 patients with symptoms of corticosteroid deficiency. Amplitude of $T$ patients with symptoms of corticosteroid deficiency, Amplitude
wave fell to under $50 \%$ of the pre-withdrawal value in 13.

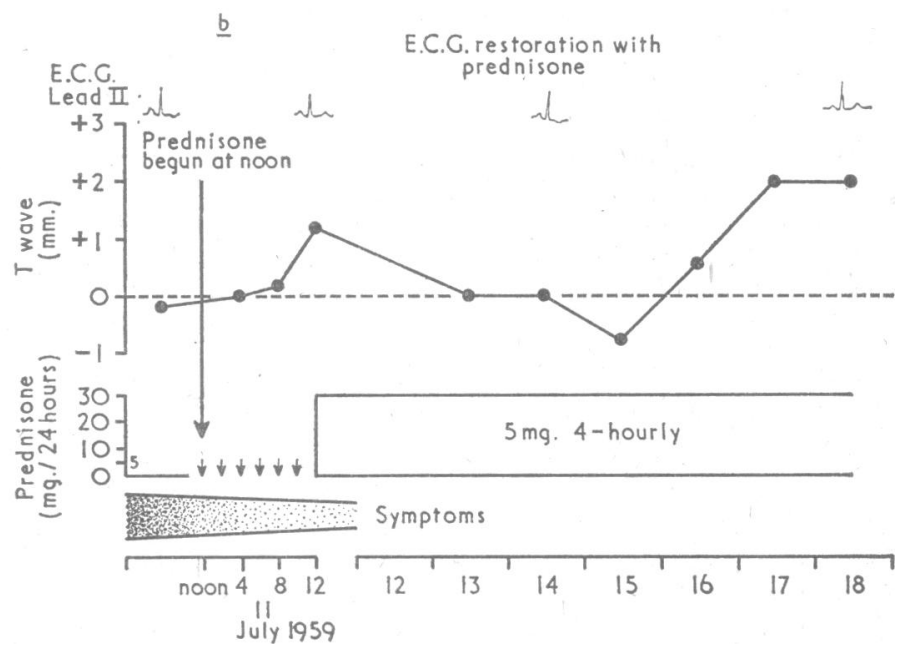

FIG. 1.-Daily T-wave amplitudes fell in lead II during a steroid withdrawal (above) which required 10 days to produce a clear clinical picture of cortisol insufficiency. A rise in T-wave amplitude followed steroid repletion (below). 
considerable degree of corticosteroid deficiency. However, she remained well throughout this period and had a normal neck uptake of radioiodine.

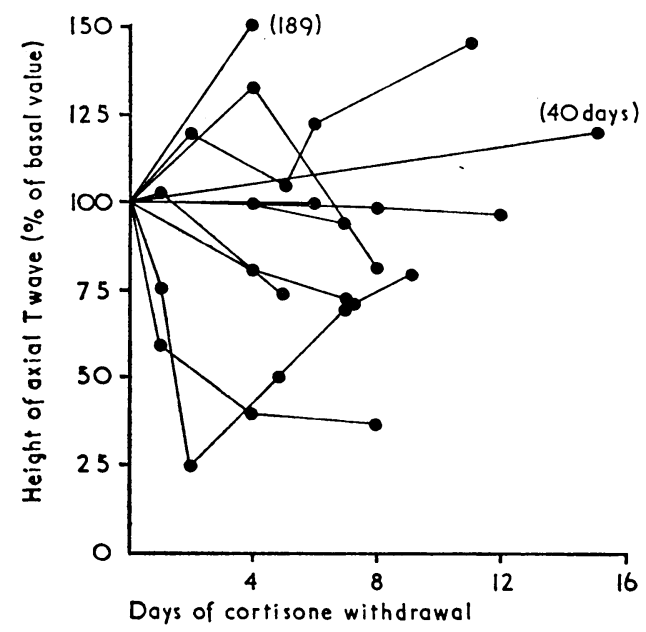

FIG. 3.-Effect of cortisone withdrawal on height of axial $\mathrm{T}$ wave in 12 patients without clinical evidence of steroid insufficiency; only two showed a halving of the T-wave amplitude (one temporarily).

\section{Other E.C.G. Changes}

The second most frequently noted change in the E.C.G. was a prolongation of the $\mathrm{Q}-\mathrm{T}_{\mathrm{c}}$ interval to $0.44-0.50$, which occurred in 6 of the 16 corticosteroid-dependent patients and in none of the other group. Three patients, all in the corticosteroid-dependent group, showed a fall in the voltage of the QRS complex. All these changes were confined to those patients whose E.C.G.s also showed the T-wave changes already described.

\section{Discussion}

This analysis of the changes in the E.C.G. which occurred on withdrawal of maintenance corticosteroid therapy in patients with varying degrees of hypopituitarism showed a high incidence of abnormalities in patients who were found to be steroiddependent. Thus $13(81 \%)$ out of the 16 such patients developed flattening or inversion of the $\mathrm{T}$ waves in the standard and unipolar limb leads, six (38\%) showed a prolongation of the Q- $T_{c}$ interval, and three $(19 \%)$ showed a fall in the voltage of the QRS complex. In contrast, only 2 out of 12 patients who did not manifest any symptoms of corticosteroid deficiency during the withdrawal developed similar changes on the E.C.G., and in one this was but temporary.

Previous reports of changes in the E.C.G. in spontaneous hypopituitarism have also emphasized the frequency of flattening or inversion of the $\mathrm{T}$ waves. This was found in $95 \%$ of the 20 patients in one series (Kosowicz and Roguska, 1963). These authors also found that the E.C.G. in $65 \%$ of their patients showed depression of the S-T segments, and that $55 \%$ showed a lowering of the voltage of the QRS complexes, and prolongation of the $\mathrm{Q}-\mathrm{T}_{\mathrm{c}}$ interval.

Somerville et al. (1951) studied the E.C.G.s of 90 patients with Addison's disease and found the tracing to be abnormal in 47. The most frequently occurring abnormality was a flattening or inversion of the $\mathrm{T}$ waves, which was found in the precordial leads in $77 \%$ of the patients with an abnormal tracing and in the standard leads in $55 \%$ of these patients. This incidence of $55 \%$ compares with the incidence of $81 \%$ found in the present study. They comment on the preponderance of females among their patients with abnormal tracings, and this may help to account for the difference between the two series, as all except two of our patients were female. It is also possible that our patients experienced more extreme corticosteroid deficiency during their period of cortisone deprivation.
The majority of our patients showed a striking regression of the E.C.G. changes after repletion with prednisone. Similarly Somerville et al. (1951) found that cortisone produced an improvement in the E.C.G. in most of their patients. In cases of spontaneous hypopituitarism combined treatment with thyroxine and cortisone is often necessary to restore the E.C.G. to normal (Bernart and de Andino, 1958; Kosowicz and Roguska, 1963).

The cause of the E.C.G. changes of corticosteroid deficiency remains uncertain. Somerville et al. (1951) were unable to establish any definite relation between these changes and the severity of the Addison's disease, as assessed by the eosinophil response to A.C.T.H., but did find a higher incidence of E.C.G. abnormality the lower the basal metabolic rate of the patient Wilson and Miller (1953) found that their four cases of Addison's disease with an abnormal E.C.G. had values for the total exchangeable sodium which were either elevated or at the upper limit of normal, probably due to previous treatment with deoxycortone acetate. Treatment of these patients with cortisone not only produced an improvement of the E.C.G. but also lowered the total exchangeable sodium. This effect was not found in three patients with Addison's disease who had normal E.C.G.s. Five of the 13 patients in the present series who developed changes of the E.C.G. had estimations of the serum electrolytes performed both before cortisone withdrawal and again at the height of their symptoms of corticosteroid deficiency; in none of them was any abnormality of the serum electrolytes found. It therefore seems unlikely that changes in the concentration of serum electrolytes are responsible for the E.C.G. abnormalities, though, as suggested by the studies of Wilson and Miller, changes in the distribution of electrolytes within intravascular and extravascular compartments may play an important part.

As we have found reversible changes of the $T$ waves of the E.C.G. in a high proportion of cases with acute cortisol deficiency, we have come to regard these changes as providing useful objective evidence of cortisol deficiency. However, as we and others have had definite instances of the syndrome without such E.C.G. changes, their absence cannot be taken to exclude the presence of cortisol deficiency.

\section{Summary}

Cortisone therapy was withdrawn to permit the assessment of adrenocortical function in 28 patients previously treated by ${ }^{90} \mathrm{Y}$ pituitary implantation for disseminated carcinoma of the breast or prostate. Serial E.C.G.s were taken before and during the withdrawals, and also during subsequent corticosteroid repletion. Thirteen out of 16 patients who developed symptoms of cortisol deficiency showed persistent flattening or inversion of the $T$ waves of the axial standard lead. Only one out of 12 patients who did not develop such symptoms also showed these changes. The value of the E.C.G. in providing objective evidence of cortisol deficiency is emphasized, though the absence of such changes does not exclude the condition.

We are grateful to Dr. Brian Pentecost for his help in assessing the E.C.G.s and to Professor Russell Fraser, who was in charge of all the patients studied, for his help and encouragement. Most of the patients were studied by G. F. J. as part of a Ph.D. thesis.

\section{REFERENCES}

Bernart, W. F., and de Andino, A. M., jun. (1958). Amer. Heart 7., 55,

Coelho, E. (1932). Bull. Soc. méd. Hôp. Paris, 48, 285

Delius, L., and Opitz, R. (1935). Dtsch. Arch. klin. Med., 178, 1.

Fraser, R., and Joplin, G. F. (1961). Therapeutic Pituitary Ablation in Modern Trends of Endocrinology, edited by H. Gardiner-Hill, p. 69. London.

Joplin, G. F. (1965). Ph.D. Thesis, University of London.

Kosowicz, J., and Roguska, J. (1963). Amer. Heart f., 65, 17.

Norymberski, J. K., Stubbs, R. D., and West, H. F.'(1953). Lancet, 1, 1276.

Sheehan, H. L., and Summers, V. K. (1949). Quart. F. Med., 18, 319.

Somerville, W., Levine, H. D., and Thorn, G. W. (1951). Medicine (Baltimore), 30, 43 .

Wilson, G. M., and Miller, H. (1953). Clin. Sci., 12, 113. 